\title{
Safety and Tolerability of Empagliflozin in Patients with Type 2 Diabetes: Pooled Analysis of Phase I-III Clinical Trials
}

\author{
Sven Kohler $\cdot$ Cordula Zeller $\cdot$ Hristo Iliev $\cdot$ Stefan Kaspers
}

Received: May 22, 2017 / Published online: June 19, 2017

(C) The Author(s) 2017. This article is an open access publication

\begin{abstract}
Introduction: We characterized the safety and tolerability of empagliflozin in patients with type 2 diabetes (T2DM) randomized 1:1:1 to placebo, empagliflozin $10 \mathrm{mg}$, or empagliflozin $25 \mathrm{mg}$ in clinical trials.

Methods: Pooled data were analyzed from patients with T2DM treated with placebo $(N=4203)$, empagliflozin $10 \mathrm{mg}(N=4221)$, or empagliflozin $25 \mathrm{mg}(N=4196)$ in 15 randomized phase I-III trials plus four extension studies. Adverse events (AEs) were assessed descriptively in participants who took at least one dose of study drug. AE incidence rates per 100 patient-years were calculated to adjust for differences in drug exposure between trials.
\end{abstract}

Enhanced content To view enhanced content for this article go to http://www.medengine.com/Redeem/ D998F0607B2770E3.

Electronic supplementary material The online version of this article (doi:10.1007/s12325-017-0573-0) contains supplementary material, which is available to authorized users.

S. Kohler $(\bowtie) \cdot H$. Iliev $\cdot$ S. Kaspers

Boehringer Ingelheim Pharma GmbH \& Co. KG, Binger Strasse 173, 55216 Ingelheim, Germany e-mail: sven.kohler@boehringer-ingelheim.com

C. Zeller

Boehringer Ingelheim Pharma GmbH, Birkendorfer Strasse 65, 88400 Biberach an der Riss, Germany
Results: Total exposure was 7369,7782 , and 7754 patient-years in the placebo, empagliflozin $10 \mathrm{mg}$, and $25 \mathrm{mg}$ groups, respectively. The incidence of any AEs, severe AEs, serious AEs, and AEs leading to discontinuation was no higher in participants treated with empagliflozin vs. placebo. Empagliflozin was not associated with an increased risk of hypoglycemia vs. placebo, except in participants on background sulfonylurea. The incidence of events consistent with urinary tract infection was similar across treatment groups (8.7-9.5/ 100 patient-years). Events consistent with genital infection occurred more frequently in participants treated with empagliflozin 10 and $25 \mathrm{mg}$ (3.5 and 3.4/100 patient-years, respectively) than placebo (0.9/100 patient-years). The incidence of AEs consistent with volume depletion was similar across treatment groups (1.7-1.9/100 patient-years) but was higher with empagliflozin $10 \mathrm{mg}$ and $25 \mathrm{mg}$ vs. placebo in participants aged 75 years or older $(3.2$ and 3.0 vs. $2.3 / 100$ patient-years, respectively). The rates of bone fractures, cancer events, renal AEs, venous thromboembolic events, hepatic injury, acute pancreatitis, lower limb amputations, and diabetic ketoacidosis were similar across treatment groups.

Conclusion: This analysis of pooled safety data based on more than 15,000 patient-years' exposure supports a favorable benefit-risk profile of empagliflozin in patients with T2DM. 
Funding: Boehringer Ingelheim Pharma $\mathrm{GmbH}$.

Keywords: Adverse drug event; Adverse drug reaction; Drug side effects; Hypoglycemia; Ketoacidosis; SGLT2 inhibitor

\section{INTRODUCTION}

Empagliflozin is a potent and selective sodium glucose cotransporter 2 (SGLT2) inhibitor used in the treatment of type 2 diabetes mellitus (T2DM). Inhibition of SGLT2 in patients with T2DM leads to increased urinary glucose excretion [1]. In addition, initiation of empagliflozin increases excretion of sodium, resulting in osmotic diuresis and reduced volume load $[2,3]$. In placebo-controlled phase III trials, treatment with empagliflozin (10 or $25 \mathrm{mg}$ ) as monotherapy or add-on therapy improved glycemic control and led to reductions in weight and blood pressure in patients with T2DM [4-11]. Furthermore, in the EMPA-REG OUT$\mathrm{COME}^{\circledR}$ trial, empagliflozin given in addition to standard of care reduced cardiovascular events, cardiovascular mortality, and incident or worsening nephropathy in patients with T2DM and established cardiovascular disease [12, 13].

An analysis of pooled safety data from clinical trials based on more than 9000 patient-years' exposure showed that empagliflozin 10 and $25 \mathrm{mg}$ were well tolerated in patients with T2DM [14]. Events consistent with genital infection were reported in a greater proportion of patients treated with empagliflozin than placebo. Empagliflozin was not associated with an increased risk of hypoglycemia vs. placebo, except in patients on background sulfonylurea and/or insulin. In this clinical trial setting, the incidences of events consistent with urinary tract infection (UTI), volume depletion, bone fractures, cancer, and decreased renal function were not increased with empagliflozin [14]. However, side effects in the empagliflozin product label include UTIs and volume depletion, especially in elderly patients [15].

An increased risk of diabetic ketoacidosis was not observed in clinical trials of empagliflozin. However, as loss of glucose in the urine leads to a negative energy balance and so to a decreased insulin-to-glucagon ratio, SGLT2 inhibition may lead to an increase in circulating ketone bodies, particularly in the fasting state [16], and there have been reports of diabetic ketoacidosis in post-marketing safety studies. Thus, the product label for empagliflozin includes a recommendation for healthcare professionals to assess patients who present with signs and symptoms of metabolic acidosis for ketoacidosis regardless of blood glucose level [15].

This paper describes the safety and tolerability of empagliflozin based on a large pool of patients with T2DM who were randomized 1:1:1 to empagliflozin $10 \mathrm{mg}$, empagliflozin $25 \mathrm{mg}$, or placebo in 15 phase I-III clinical trials, including the EMPA-REG OUTCOME ${ }^{\circledR}$ trial.

\section{METHODS}

\section{Participants}

Data were pooled from 14 trials of 8 days to 78 weeks' duration [4-11, 17-22]; the 52-week extensions to the phase III trials of empagliflozin given as monotherapy, or as add on to metformin, metformin plus SU, and pioglitazone with or without metformin [23-26]; and the cardiovascular outcomes trial EMPA-REG OUTCOME ${ }^{\circledR}$ (median duration of treatment 2.6 years) [13].

All procedures followed were in accordance with the ethical standards of the responsible committee on human experimentation (institutional and national) and with the Helsinki Declaration of 1964, as revised in 2013. An independent ethics committee or institutional review board approved the clinical protocol at each participating center. All participants gave signed and dated informed consent prior to inclusion.

\section{Assessments and Data Analyses}

Safety and tolerability were assessed on the basis of adverse events (AEs) reported by investigators, which were coded according to preferred terms in the Medical Dictionary for Regulatory Activities [MedDRA] version 18.0. A severe AE was defined as an AE judged by the investigator to be incapacitating or causing inability to work or to 
Table 1 Demographics and baseline characteristics

\begin{tabular}{|c|c|c|c|}
\hline & $\begin{array}{l}\text { Placebo } \\
(N=4203)\end{array}$ & $\begin{array}{l}\text { Empagliflozin } 10 \mathrm{mg} \\
(N=4221)\end{array}$ & $\begin{array}{l}\text { Empagliflozin } 25 \mathrm{mg} \\
(N=4196)\end{array}$ \\
\hline Male, $n(\%)$ & $2700(64.2)$ & $2731(64.7)$ & $2745(65.4)$ \\
\hline Age, years & $60.6(9.7)$ & $60.7(9.5)$ & $60.6(9.7)$ \\
\hline \multicolumn{4}{|l|}{ Race, $n(\%)$} \\
\hline White & $2765(65.8)$ & $2811(66.6)$ & $2787(66.4)$ \\
\hline Asian & $1219(29.0)$ & 1209 (28.6) & $1198(28.6)$ \\
\hline Black/African-American & $183(4.4)$ & $171(4.1)$ & $174(4.1)$ \\
\hline Other $^{\mathrm{a}}$ & $36(0.9)$ & $29(0.7)$ & $35(0.8)$ \\
\hline Missing & 0 & $1(<0.1)$ & $2(<0.1)$ \\
\hline \multicolumn{4}{|l|}{ Region, $n(\%)$} \\
\hline Europe & $1656(39.4)$ & $1662(39.4)$ & $1652(39.4)$ \\
\hline Asia & $1124(26.7)$ & $1122(26.6)$ & $1111(26.5)$ \\
\hline $\begin{array}{l}\text { North America } \\
\text { (plus Australia and New Zealand) }\end{array}$ & $857(20.4)$ & $868(20.6)$ & $859(20.5)$ \\
\hline Latin America & $450(10.7)$ & $452(10.7)$ & $456(10.9)$ \\
\hline Africa/Middle East & $116(2.8)$ & $117(2.8)$ & $118(2.8)$ \\
\hline \multicolumn{4}{|l|}{ Time since diagnosis, years, $n(\%)$} \\
\hline$\leq 1$ & $227(5.4)$ & $252(6.0)$ & $256(6.1)$ \\
\hline$>1-5$ & $922(21.9)$ & $858(20.3)$ & $860(20.5)$ \\
\hline$>5$ & $3039(72.3)$ & $3096(73.3)$ & $3064(73.0)$ \\
\hline Missing & $15 \quad(0.4)$ & $15(0.4)$ & $16(0.4)$ \\
\hline \multicolumn{4}{|c|}{ Number of background glucose-lowering medications, $n$ (\%) } \\
\hline 0 & $525(12.5)$ & $523(12.4)$ & $524(12.5)$ \\
\hline 1 & $1212(28.8)$ & $1221(28.9)$ & $1175(28.0)$ \\
\hline 2 & $1880(44.7)$ & $1862(44.1)$ & $1900(45.3)$ \\
\hline Other & $586(13.9)$ & $615(14.6)$ & $597(14.2)$ \\
\hline Weight, $\mathrm{kg}^{\mathrm{b}}$ & $85.5(19.6)$ & $85.3(19.5)$ & $85.8(19.6)$ \\
\hline BMI, $\mathrm{kg} / \mathrm{m}^{2 \mathrm{c}}$ & $30.4(5.4)$ & $30.4(5.5)$ & $30.5(5.5)$ \\
\hline HbAlc, $\%^{\mathrm{d}}$ & $8.06(0.83)$ & $8.05(0.84)$ & $8.04(0.83)$ \\
\hline $\mathrm{FPG}, \mathrm{mmol} / \mathrm{L}^{\mathrm{e}}$ & $8.55(2.31)$ & $8.54(2.33)$ & $8.52(2.30)$ \\
\hline SBP, $\mathrm{mmHg}^{\mathrm{f}}$ & $134.3(16.6)$ & $133.9(16.2)$ & $134.1(16.5)$ \\
\hline $\mathrm{DBP}, \mathrm{mmHg}^{\mathrm{f}}$ & $77.9(9.7)$ & $77.8(9.6)$ & $77.8(9.4)$ \\
\hline $\mathrm{eGFR}, \mathrm{mL} / \mathrm{min} / 1.73 \mathrm{~m}^{2} \mathrm{~g}$ & $79.1(21.0)$ & $79.3(21.5)$ & $79.2(21.6)$ \\
\hline
\end{tabular}


Table 1 continued

\begin{tabular}{lccc}
\hline & $\begin{array}{l}\text { Placebo } \\
(\boldsymbol{N}=\mathbf{4 2 0 3})\end{array}$ & $\begin{array}{l}\text { Empagliflozin 10 mg } \\
(\boldsymbol{N = 4 2 2 1})\end{array}$ & $\begin{array}{l}\text { Empagliflozin 25 mg } \\
(\boldsymbol{N}=\mathbf{4 1 9 6})\end{array}$ \\
\hline eGFR, $\mathrm{mL} / \mathrm{min} / 1.73 \mathrm{~m}^{2}, n(\%)$ & & & $1233(29.4)$ \\
$\geq 90$ & $1172(27.9)$ & $1204(28.5)$ & $2216(52.8)$ \\
60 to $<90$ & $2298(54.7)$ & $2285(54.1)$ & $728(17.3)$ \\
30 to $<60$ & $726(17.3)$ & $722(17.1)$ & $16(0.4)$ \\
$<30$ & $7(0.2)$ & $9(0.2)$ & $3(0.1)$ \\
\hline
\end{tabular}

Data are mean (SD), unless otherwise indicated, in participants who received at least one dose of study drug $B M I$ body mass index, eGFR estimated glomerular filtration rate by Modification of Diet in Renal Disease (MDRD) equation, $D B P$ diastolic blood pressure, $F P G$ fasting plasma glucose, $H b A 1 c$ glycosylated hemoglobin, $S B P$ systolic blood pressure, $T 2 D M$ type 2 diabetes

a American Indian/Alaska Native/Hawaiian/Pacific Islander

b Placebo, $n=4182$; empagliflozin $10 \mathrm{mg}, n=4201$; empagliflozin $25 \mathrm{mg}, n=4177$

c Placebo, $n=4182$; empagliflozin $10 \mathrm{mg}, n=4201$; empagliflozin $25 \mathrm{mg}, n=4177$

d Placebo, $n=4203$; empagliflozin $10 \mathrm{mg}, n=4219$; empagliflozin $25 \mathrm{mg}, n=4195$

e Placebo, $n=4176$; empagliflozin $10 \mathrm{mg}, n=4194$; empagliflozin $25 \mathrm{mg}, n=4180$

f Placebo, $n=4145$; empagliflozin $10 \mathrm{mg}, n=4165$; empagliflozin $25 \mathrm{mg}, n=4142$

g Placebo, $n=4203$; empagliflozin $10 \mathrm{mg}, n=4220$; empagliflozin $25 \mathrm{mg}, n=4193$

perform usual activities. A serious $\mathrm{AE}$ was defined as an $\mathrm{AE}$ that resulted in death, was immediately life-threatening, resulted in persistent or marked disability/incapacity, required or prolonged patient hospitalization, was a congenital anomaly/birth defect, or was deemed serious for any other reason. Safety topics of interest included confirmed hypoglycemic AEs (plasma glucose $\leq 3.9 \mathrm{mmol} / \mathrm{L}$ and/or requiring assistance); events consistent with UTI, genital infection, and volume depletion; bone fractures; cancer; decreased renal function; diabetic ketoacidosis; hepatic injury; acute pancreatitis; and amputations. As lower limb amputations were not usually captured in $\mathrm{AE}$ reports, the frequency of lower limb amputations was assessed on the basis of a manual review of the pooled safety data and AE narratives. Assessment of laboratory parameters included changes from baseline in hematocrit, parathyroid hormone, liver enzymes, bilirubin, electrolytes, and lipids, and estimated glomerular filtration rate (eGFR; according to the Modification of Diet in Renal Disease equation). Urine ketone levels (negative [normal], trace, $1+, \geq 2+, \geq 3+$ ) were assessed on the basis of the worst recorded value on treatment.

Analyses of AEs were descriptive and based on participants who received at least one dose of study drug. Exposure-adjusted incidence rates were calculated per 100 patient-years as $100 \times n / T$, where $n$ was the number of subjects with the event and $T$ was the total patient-years at risk of the event. Patient-years at risk was defined as the time from the first dose to the onset of the first event (for participants with an event) or to the last dose plus 7 days (for participants without an event).

\section{RESULTS}

\section{Participant Disposition, Exposure and Baseline Characteristics}

In total, 4203, 4221, and 4196 participants were treated with placebo, empagliflozin $10 \mathrm{mg}$, and empagliflozin $25 \mathrm{mg}$, respectively. Total exposure was 7369,7782 , and 7754 patient-years in the placebo, empagliflozin $10 \mathrm{mg}$, and 
empagliflozin $25 \mathrm{mg}$ groups, respectively. The participants came from Europe (39\%), Asia (27\%), North America (21\%), and Latin America (11\%) (Table 1). Baseline demographics and clinical characteristics were balanced among the treatment groups (Table 1).

\section{Summary of Adverse Events}

The incidences of severe AEs, serious AEs, fatal AEs, and AEs leading to discontinuation were higher in the placebo group than in the empagliflozin groups (Table 2). The most common

Table 2 Summary of adverse events

\begin{tabular}{|c|c|c|c|c|c|c|}
\hline & \multicolumn{2}{|c|}{ Placebo $(N=4203)$} & \multicolumn{2}{|c|}{$\begin{array}{l}\text { Empagliflozin } 10 \mathrm{mg} \\
(N=4221)\end{array}$} & \multicolumn{2}{|c|}{$\begin{array}{l}\text { Empagliflozin } 25 \mathrm{mg} \\
(N=4196)\end{array}$} \\
\hline & $n(\%)$ & $\begin{array}{l}\text { Rate/100 } \\
\text { patient-years }\end{array}$ & $n(\%)$ & $\begin{array}{l}\text { Rate } / 100 \\
\text { patient-years }\end{array}$ & $n(\%)$ & $\begin{array}{l}\text { Rate/100 } \\
\text { patient-years }\end{array}$ \\
\hline$\geq 1 \mathrm{AE}$ & $3449(82.1)$ & 195.4 & $3401(80.6)$ & 167.2 & $3383(80.6)$ & 163.6 \\
\hline$\geq 1$ drug-related $\mathrm{AE}^{\mathrm{a}}$ & $921(21.9)$ & 14.9 & $1144(27.1)$ & 18.6 & $1117(26.6)$ & 18.1 \\
\hline $\begin{aligned} \geq 1 \text { AE leading to } \\
\text { discontinuation }\end{aligned}$ & $540(12.8)$ & 7.6 & $490(11.6)$ & 6.5 & $484(11.5)$ & 6.4 \\
\hline$\geq 1$ severe $\mathrm{AE}^{\mathrm{b}}$ & $718(17.1)$ & 10.8 & $634(15.0)$ & 8.9 & $682(16.3)$ & 9.6 \\
\hline$\geq 1$ serious $\mathrm{AE}^{\mathrm{c}}$ & $1150(27.4)$ & 19.2 & $1020(24.2)$ & 15.5 & $1052(25.1)$ & 16.5 \\
\hline Fatal AE & $122(2.9)$ & 1.6 & $100(2.4)$ & 1.3 & $83(2.0)$ & 1.1 \\
\hline \multicolumn{7}{|c|}{ AEs with frequency of $\geq 5 \%$ in any group (by MedDRA preferred term) } \\
\hline Hypoglycemia & $956(22.7)$ & 16.1 & $977(23.1)$ & 15.9 & $952(22.7)$ & 15.5 \\
\hline Hyperglycemia & $709(16.9)$ & 11.0 & $346(8.2)$ & 4.7 & $306(7.3)$ & 4.1 \\
\hline Urinary tract infection & $523(12.4)$ & 7.7 & $528(12.5)$ & 7.4 & $510(12.2)$ & 7.2 \\
\hline Nasopharyngitis & $424(10.1)$ & 6.1 & $417(9.9)$ & 5.7 & $408(9.7)$ & 5.6 \\
\hline $\begin{array}{l}\text { Upper respiratory tract } \\
\text { infection }\end{array}$ & $292(6.9)$ & 4.2 & $285(6.8)$ & 3.8 & $288(6.9)$ & 3.9 \\
\hline Hypertension & $291(6.9)$ & 4.1 & $205(4.9)$ & 2.7 & $218(5.2)$ & 2.9 \\
\hline Back pain & $238(5.7)$ & 3.3 & $232(5.5)$ & 3.1 & $253(6.0)$ & 3.4 \\
\hline Dizziness & $208(4.9)$ & 2.9 & $246(5.8)$ & 3.3 & $250(6.0)$ & 3.4 \\
\hline Diarrhea & $247(5.9)$ & 3.5 & $219(5.2)$ & 2.9 & $212(5.1)$ & 2.8 \\
\hline Bronchitis & $221(5.3)$ & 3.1 & $185(4.4)$ & 2.4 & $163(3.9)$ & 2.1 \\
\hline Influenza & $219(5.2)$ & 3.1 & $173(4.1)$ & 2.3 & $199(4.7)$ & 2.6 \\
\hline Arthralgia & $196(4.7)$ & 2.7 & $180(4.3)$ & 2.4 & $213(5.1)$ & 2.8 \\
\hline
\end{tabular}

Data from participants treated with at least one dose of study drug $A E$ adverse event, MedDRA Medical Dictionary for Regulatory Activities

${ }^{a}$ In opinion of investigator

b AE that is incapacitating or causing inability to work or to perform usual activities

c AE that results in death, is immediately life-threatening, results in persistent or significant disability/incapacity, requires or prolongs patient hospitalization, is a congenital anomaly/birth defect, or is deemed serious for any other reason 
AEs occurred at similar or higher incidence rates in participants treated with placebo than empagliflozin (Table 2).

\section{Hypoglycemia}

The incidence of confirmed hypoglycemic AEs differed according to glucose-lowering medication used at baseline. The incidence of confirmed hypoglycemic adverse events was higher with empagliflozin than placebo in participants taking a sulfonylurea at baseline, but was similar between empagliflozin and placebo in other subgroups by background glucose-lowering medication (Table 3).

\section{Urinary Tract Infections}

The incidence of events consistent with UTI was higher in female than male participants in all treatment groups, and was similar between empagliflozin and placebo in both male and female participants (Table 4). The incidence of such events was higher in participants aged 65 years or more in all treatment groups. Events consistent with UTI were mild or moderate in $96.7 \%$ of participants who experienced them and led to treatment discontinuation in a very small proportion of participants $(0.3 \%, 0.6 \%$, and $0.6 \%$ in the placebo, empagliflozin $10 \mathrm{mg}$, and empagliflozin $25 \mathrm{mg}$ groups, respectively). The proportions of participants with UTIs that required or prolonged hospitalization were similar in the placebo, empagliflozin $10 \mathrm{mg}$, and empagliflozin $25 \mathrm{mg}$ groups $(0.9 \%, 0.6 \%$, and $0.9 \%$, respectively). In total, 700 participants had a history of chronic or recurrent UTI, whereas 10,861 participants had no such history. Events consistent with UTI were reported by a higher proportion of participants with a history of chronic or recurrent UTI $(38.9 \%$, $37.4 \%$, and $36.5 \%$ in the placebo, empagliflozin $10 \mathrm{mg}$, and empagliflozin $25 \mathrm{mg}$ groups, respectively) than in participants without such a history $(14.4 \%, 14.4 \%$, and $13.7 \%$ in these

Table 3 Confirmed hypoglycemic adverse events by glucose-lowering medication used at baseline

\begin{tabular}{|c|c|c|c|c|c|c|c|c|c|}
\hline & \multicolumn{3}{|l|}{ Placebo } & \multicolumn{3}{|c|}{ Empagliflozin $10 \mathrm{mg}$} & \multicolumn{3}{|c|}{ Empagliflozin $25 \mathrm{mg}$} \\
\hline & $\overline{n / N}$ & $\%$ & $\begin{array}{l}\text { Rate } / 100 \\
\text { patient-years }\end{array}$ & $\overline{n / N}$ & $\%$ & $\begin{array}{l}\text { Rate } / 100 \\
\text { patient-years }\end{array}$ & $n / N$ & $\%$ & $\begin{array}{l}\text { Rate/100 } \\
\text { patient-years }\end{array}$ \\
\hline \multicolumn{10}{|c|}{ Insulin use ${ }^{a}$} \\
\hline No & $230 / 2595$ & 8.9 & 5.9 & $240 / 2612$ & 9.2 & 5.9 & $251 / 2607$ & 9.6 & 6.1 \\
\hline Yes & $676 / 1608$ & 42.0 & 31.7 & $683 / 1609$ & 42.4 & 32.1 & $659 / 1589$ & 41.5 & 31.4 \\
\hline \multicolumn{10}{|c|}{ Sulfonylurea use ${ }^{a}$} \\
\hline No & $595 / 2781$ & 21.4 & 16.9 & $575 / 2801$ & 20.5 & 15.4 & $571 / 2748$ & 20.8 & 15.7 \\
\hline Yes & $311 / 1422$ & 21.9 & 12.3 & $348 / 1420$ & 24.5 & 14.0 & $339 / 1448$ & 23.4 & 13.0 \\
\hline \multicolumn{10}{|c|}{ Metformin use $\mathrm{a}^{\mathrm{a}}$} \\
\hline No & $257 / 1275$ & 20.2 & 17.3 & $251 / 1259$ & 19.9 & 15.5 & $220 / 1255$ & 17.5 & 13.5 \\
\hline Yes & $649 / 2928$ & 22.2 & 14.2 & $672 / 2962$ & 22.7 & 14.6 & $690 / 2941$ & 23.5 & 14.9 \\
\hline \multicolumn{10}{|c|}{ Metformin alone use } \\
\hline No & $885 / 3607$ & 24.5 & 17.1 & $903 / 3583$ & 25.2 & 17.4 & $889 / 3594$ & 24.7 & 16.8 \\
\hline Yes & $21 / 596$ & 3.5 & 2.4 & $20 / 638$ & 3.1 & 1.9 & $21 / 602$ & 3.5 & 2.2 \\
\hline
\end{tabular}

Data from participants who received at least dose of study drug. Hypoglycemic adverse events are defined as those resulting in plasma glucose of at most $3.9 \mathrm{mmol} / \mathrm{L}$ and/or requiring assistance

a With or without other glucose-lowering medication 


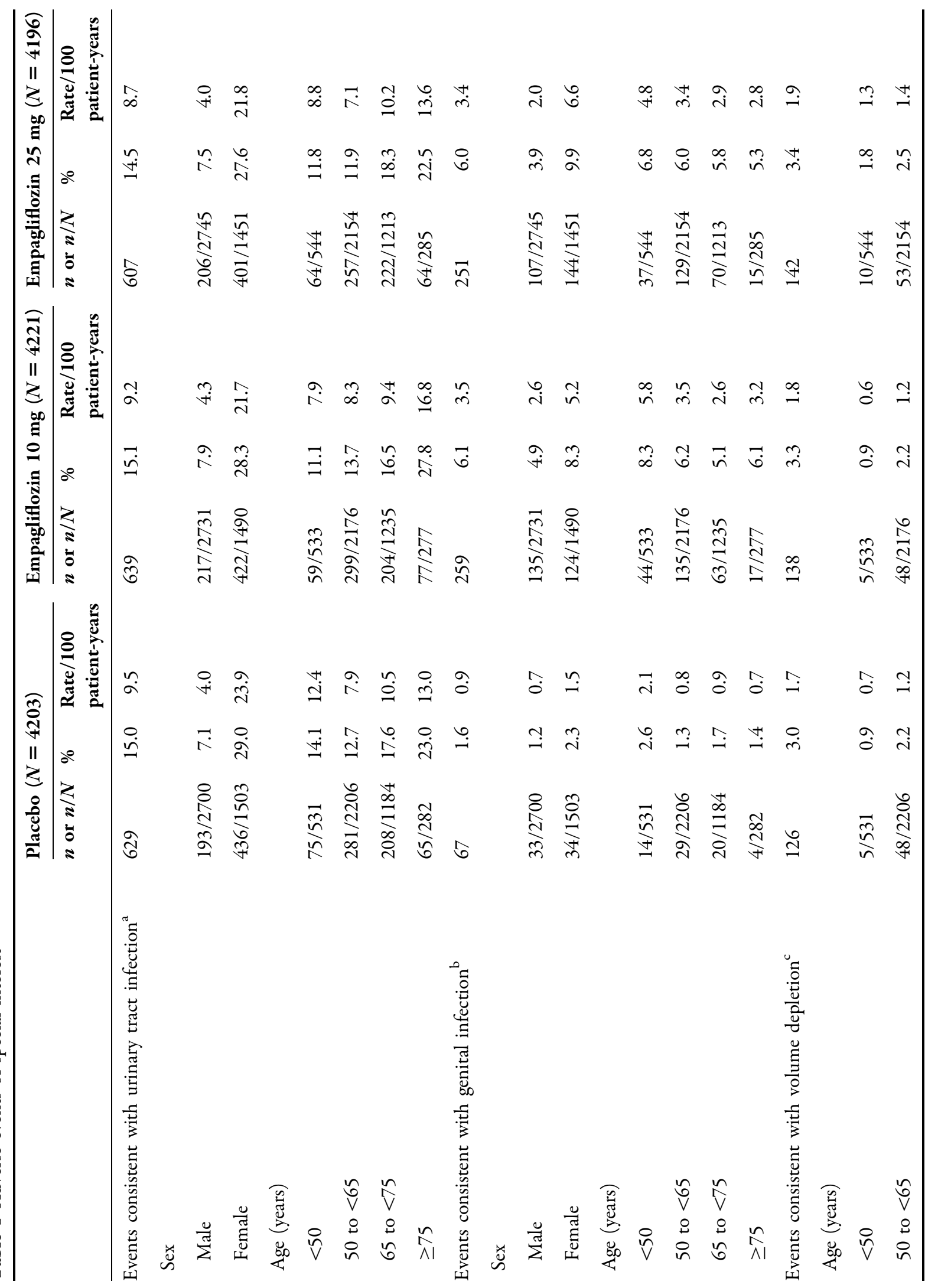




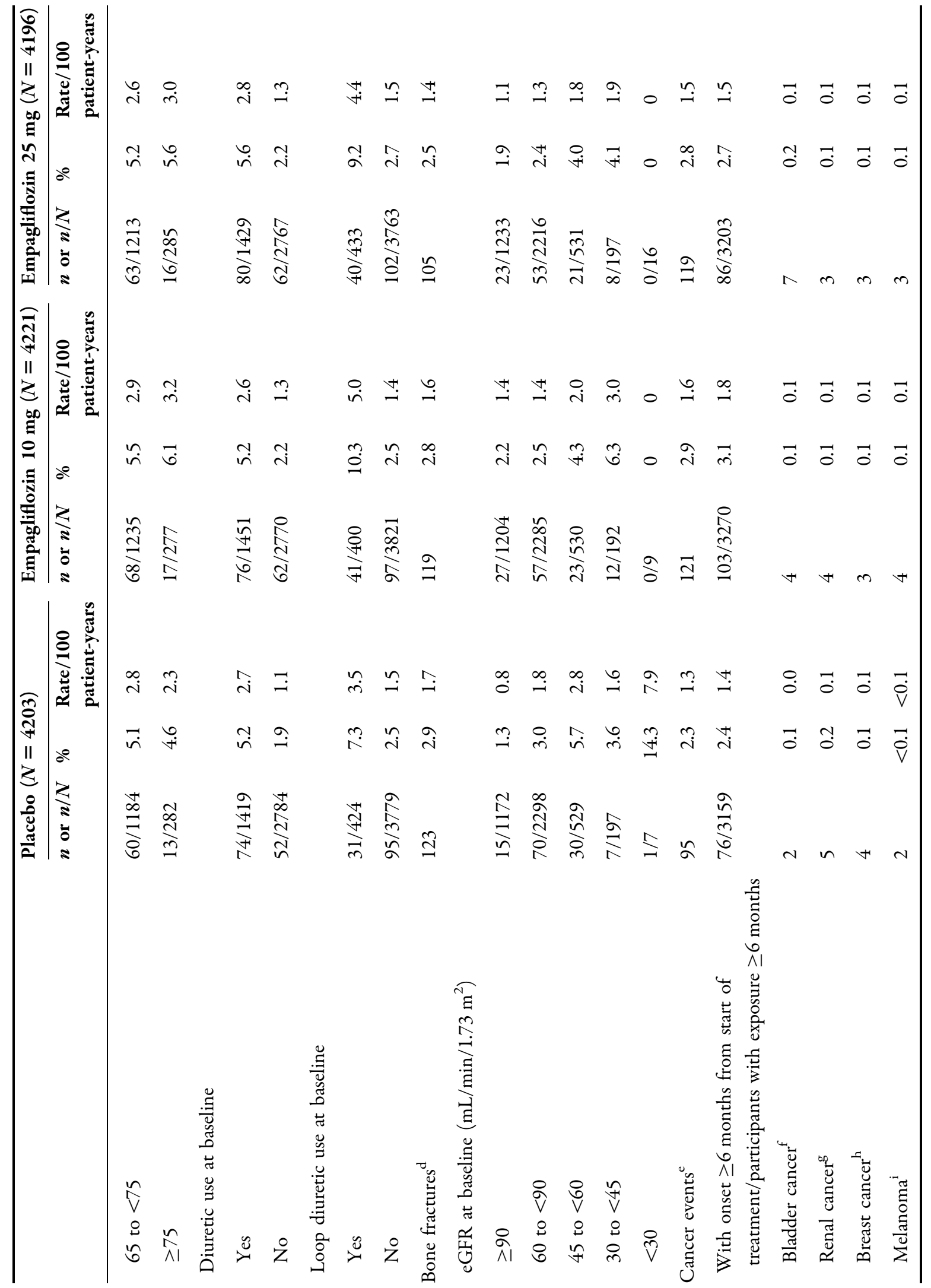




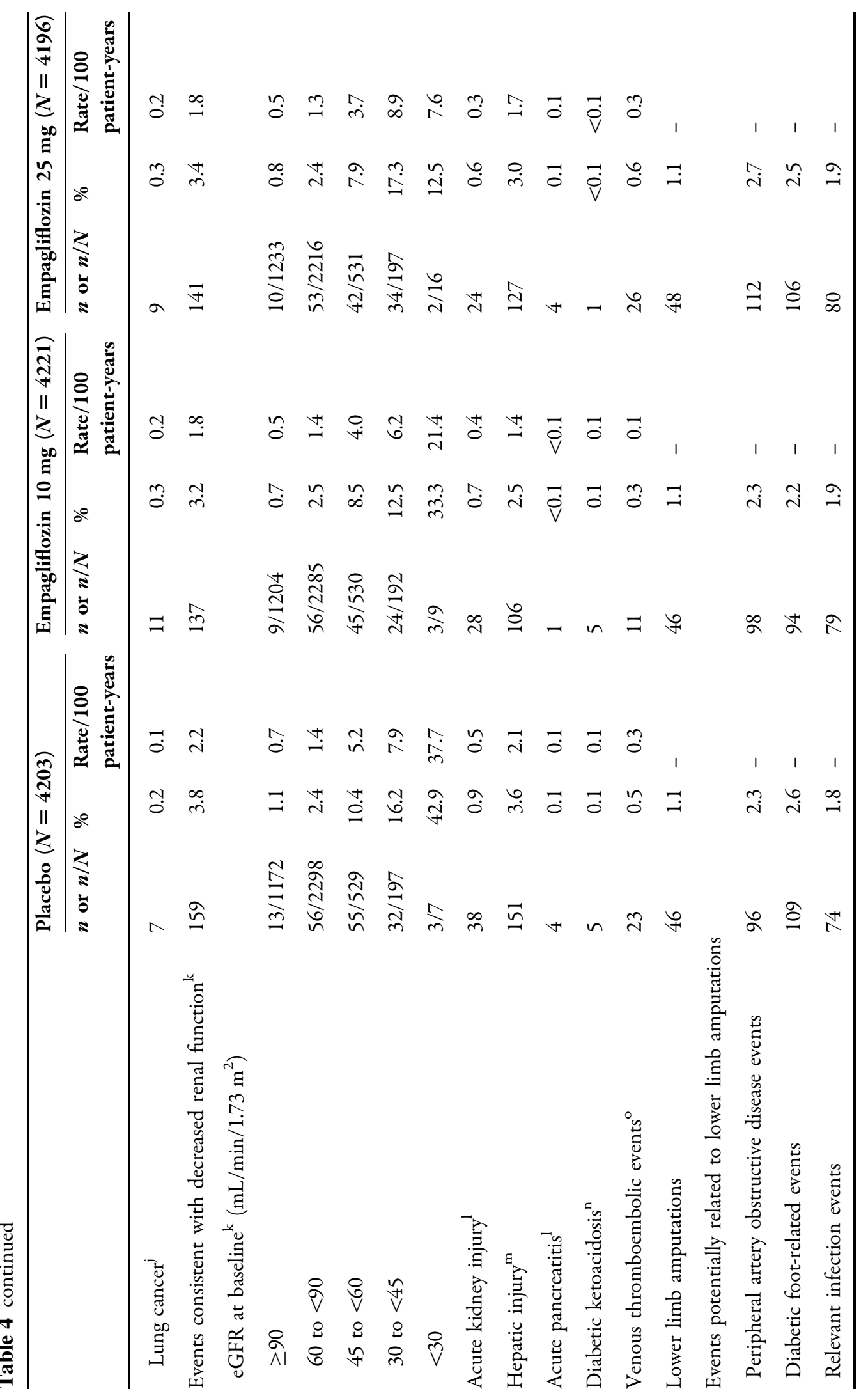




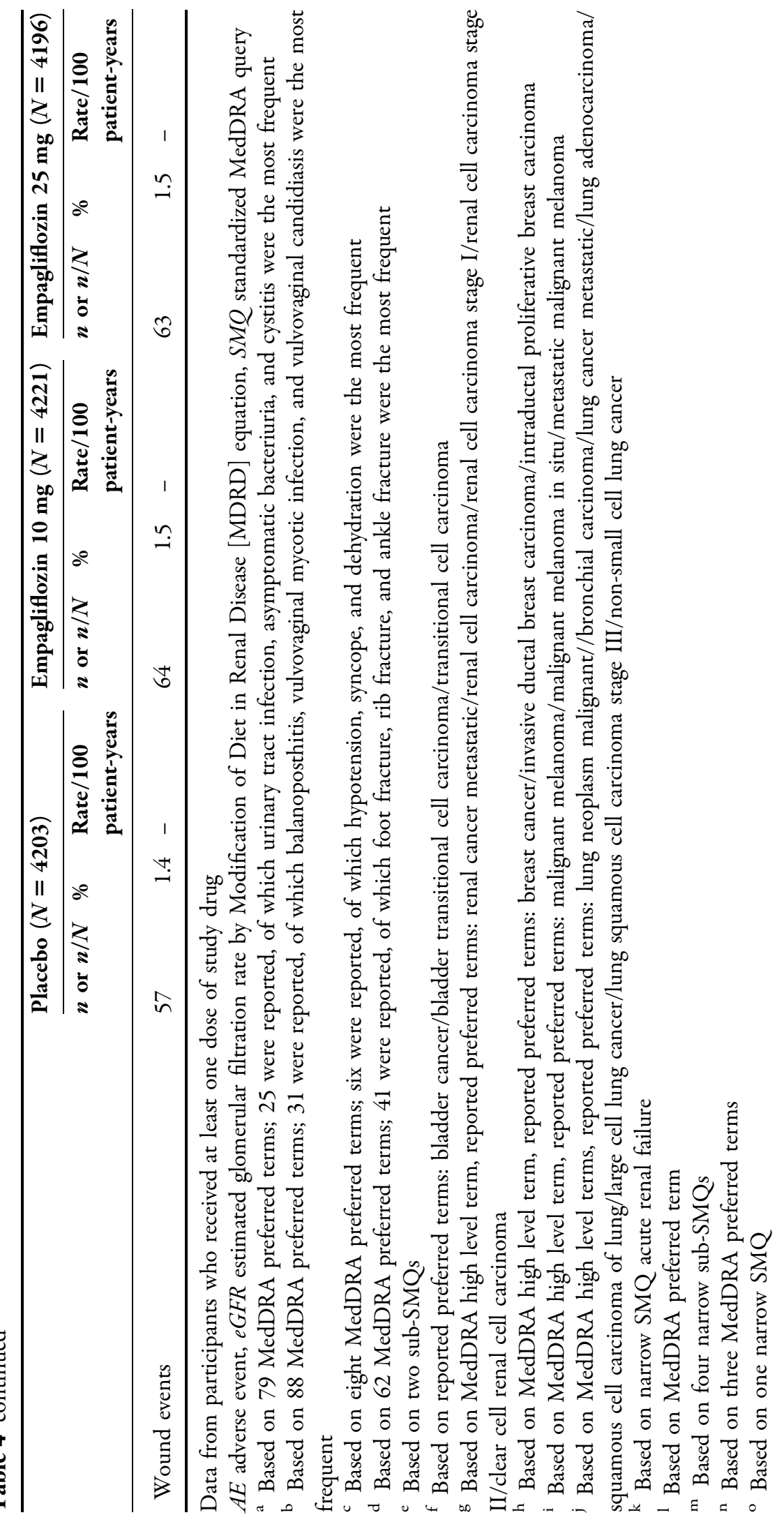


groups, respectively). Complicated UTIs (pyelonephritis, urosepsis, or serious AEs consistent with UTI) were reported in $0.9 \%, 0.6 \%$, and $0.9 \%$ of participants in the placebo, empagliflozin $10 \mathrm{mg}$, and empagliflozin $25 \mathrm{mg}$ groups, respectively. The mean change in HbA1c in patients with events consistent with UTI was not analyzed.

\section{Genital Infections}

The incidence of events consistent with genital infection was higher in female than male participants in all treatment groups, and was higher with empagliflozin than placebo in both male and female participants and in all age groups (Table 4). Events consistent with genital infection were mild or moderate in $99 \%$ of participants who experienced them and rarely led to treatment discontinuation $(<0.1 \%, 0.6 \%$, and $0.5 \%$ of participants in the placebo, empagliflozin $10 \mathrm{mg}$, and empagliflozin $25 \mathrm{mg}$ groups, respectively). The proportion of participants with genital infections reported as serious adverse events was low $(0.1 \%, 0.2 \%$, and $0.1 \%$ in the placebo, empagliflozin $10 \mathrm{mg}$, and empagliflozin $25 \mathrm{mg}$ groups, respectively). In total, 174 participants had a history of chronic or recurrent genital infection, whereas 11,387 participants had no history of chronic or recurrent genital infection. The proportion of participants with events consistent with genital infection was higher in participants with a history of chronic or recurrent genital infection $(9.7 \%, 32.0 \%$, and $27.4 \%$ in the placebo, empagliflozin $10 \mathrm{mg}$, and empagliflozin $25 \mathrm{mg}$ groups, respectively) than in participants without such a history $(1.5 \%, 5.9 \%$, and $5.9 \%$, respectively). The mean change in HbA1c in patients with events consistent with genital infection was not analyzed.

\section{Volume Depletion}

The incidence of events consistent with volume depletion was similar between placebo and empagliflozin in all age subgroups, apart from a higher incidence with empagliflozin $10 \mathrm{mg}$ and empagliflozin $25 \mathrm{mg}$ vs. placebo in participants aged 75 years or older (3.2 and 3.0 vs. 2.3 per 100 patient-years, respectively). The incidence of events consistent with volume depletion was similar between placebo and empagliflozin irrespective of use of diuretics at baseline. In participants receiving loop diuretics at baseline, the incidence of events consistent with volume depletion was 3.5, 5.0 and 4.4 per 100 patient-years with placebo, empagliflozin $10 \mathrm{mg}$, and empagliflozin $25 \mathrm{mg}$, respectively.

\section{Cancer}

The incidence of cancer events, and of cancer events with an onset more than 6 months from the start of treatment, was similar between the placebo and empagliflozin groups. No imbalance was observed between empagliflozin and placebo in the incidence of any specific type of cancer (Table 4).

\section{Renal AEs and Laboratory Parameters}

Small decreases in eGFR were observed in all treatment groups, with larger decreases in participants treated with placebo than empagliflozin (Table 5). The incidence of events consistent with decreased renal function (narrow standardized MedDRA query "acute renal failure") was similar in the placebo and empagliflozin groups; the incidence of these events was higher in participants with moderate renal impairment (eGFR $>30$ to $<60 \mathrm{~mL} / \mathrm{min} /$ $1.73 \mathrm{~m}^{2}$ ) than in those with no/mild renal impairment (Table 4). The incidence of acute kidney injury (MedDRA preferred term) was similar in the placebo and empagliflozin groups (Table 4). Serum uric acid decreased more in participants treated with empagliflozin than placebo (Table 5). Empagliflozin was not associated with an increase in the incidence of nephrolithiasis $(0.9,0.6$, and 0.5 per 100 patient-years in the placebo, empagliflozin $10 \mathrm{mg}$, and empagliflozin $25 \mathrm{mg}$ groups, respectively), renal colic $(0.1,0.2$, and 0.1 per 100 patient-years in these groups, respectively), or gout $(0.6,0.6$, and 0.5 per 100 patient-years in these groups, respectively). 


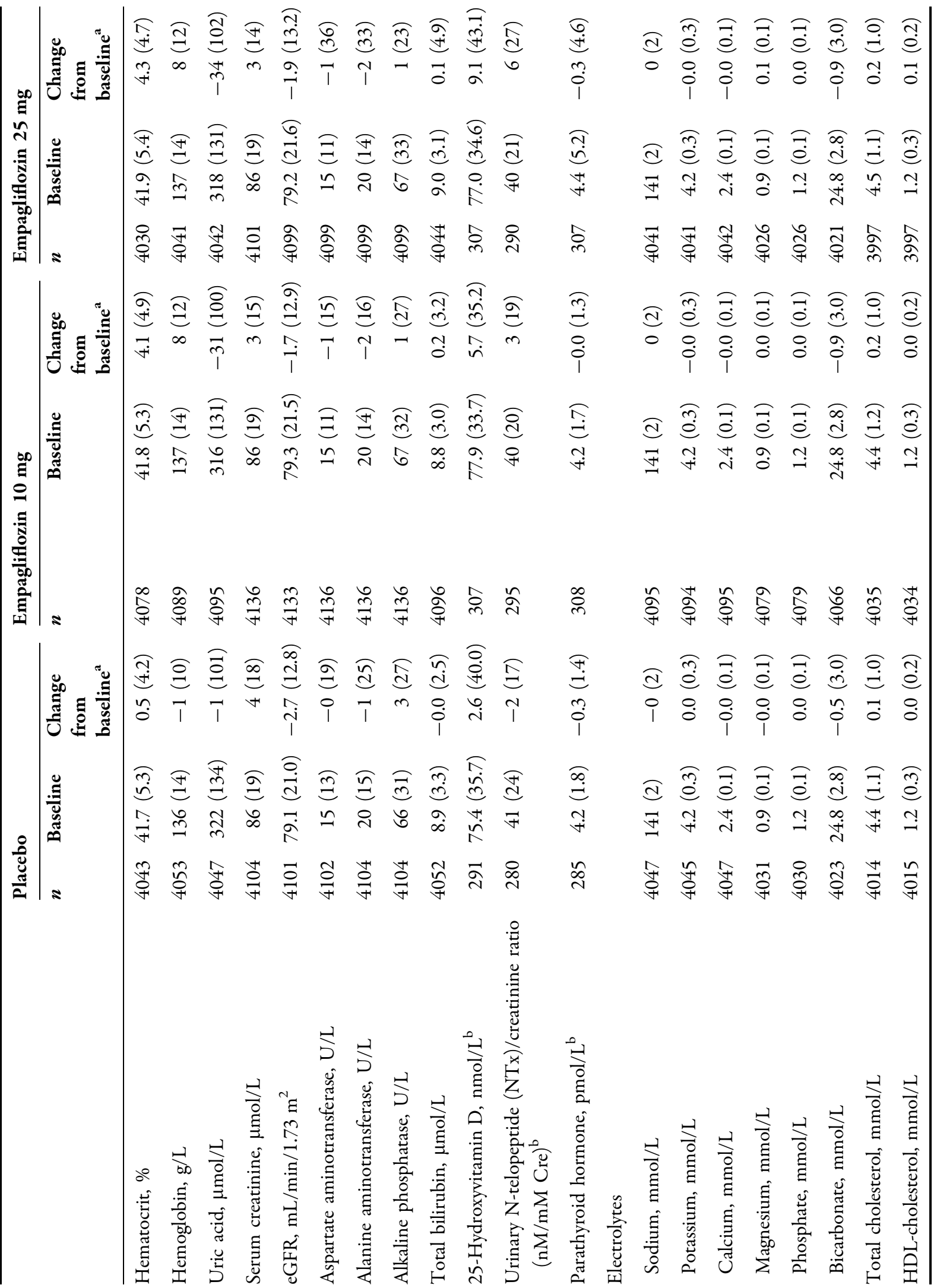




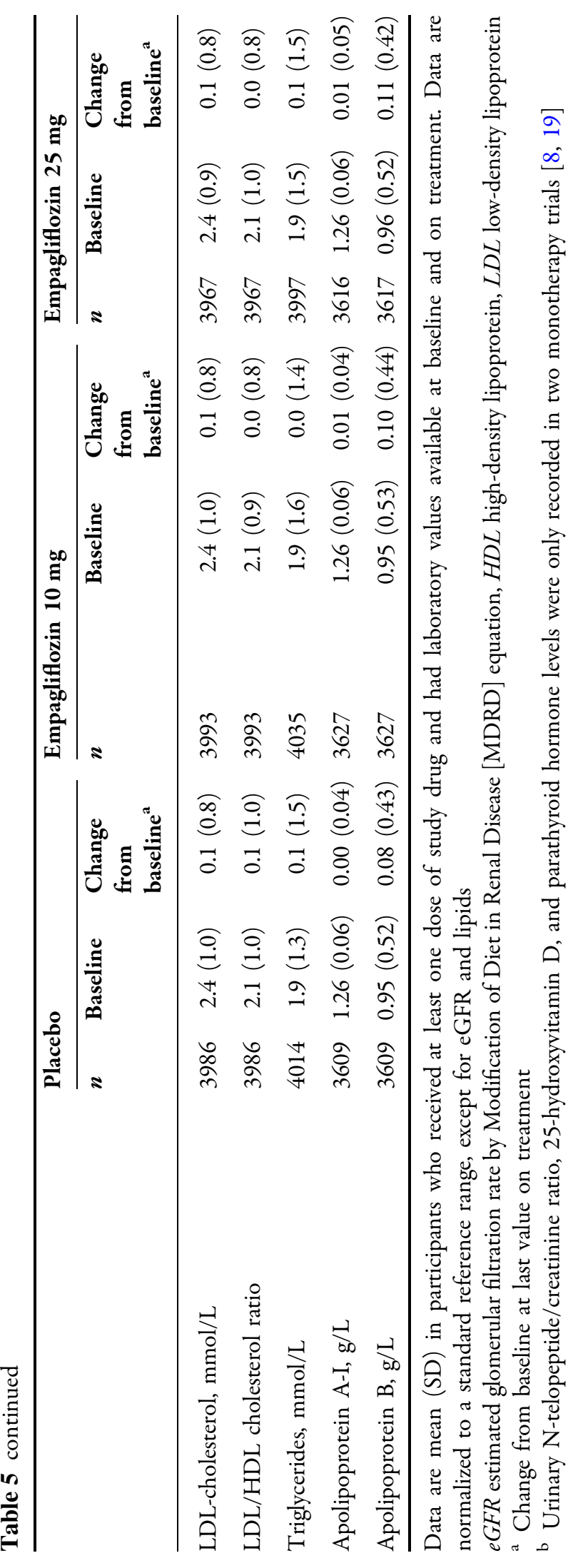




\section{Hepatic AEs and Laboratory Parameters}

The incidence of events consistent with hepatic injury was similar in the placebo and empagliflozin groups (Table 4). There were no clinically relevant changes in alanine aminotransferase (ALT), aspartate aminotransferase (AST), alkaline phosphatase, or bilirubin in any treatment group (Table 5). Elevations in liver enzymes to at least three times the upper limit of normal (ULN) were rare in all treatment groups and no more common with empagliflozin than with placebo, but elevations in ALT and/or AST at least five times ULN were more frequently observed with empagliflozin vs. placebo. The proportion of participants who had ALT and/or AST at least three times ULN with bilirubin at least two times ULN was similar in the placebo and empagliflozin groups (Table 6). Elevations in liver enzymes were mainly explained by viral infections or the effects of concomitant medication. No cases met Hy's law criteria.

\section{Hematocrit and Venous Thromboembolic Events}

Hemoglobin and hematocrit increased in participants treated with empagliflozin, with no increases in the placebo group (Table 5). The incidence of venous thromboembolic events was low in all treatment groups $(0.3,0.1$, and 0.3 per 100 patient-years in the placebo, empagliflozin $10 \mathrm{mg}$, and empagliflozin $25 \mathrm{mg}$ groups, respectively) (Table 4).

\section{Electrolytes, Parathyroid Hormone, and Bone Fractures}

No clinically meaningful changes in serum electrolytes, alkaline phosphatase, 25-hydroxyvitamin D, urinary N-telopeptide (NTx)/creatinine ratio, or parathyroid hormone were observed in any treatment group (Table 5). The incidence of bone fractures was similar across treatment groups $(1.7,1.6$, and 1.4 per 100 patient-years in the placebo, empagliflozin $10 \mathrm{mg}$, and empagliflozin $25 \mathrm{mg}$ groups, respectively). The proportion of participants with bone fractures was greater in participants with moderate renal impairment (eGFR $>30$ to $<60 \mathrm{~mL} / \mathrm{min} /$ $1.73 \mathrm{~m}^{2}$ ) than in those with no/mild renal impairment (Table 4).

\section{Lipid Parameters}

There was a small increase from baseline in LDL-cholesterol and total cholesterol in all treatment groups, including the placebo group. There was a small increase from baseline in HDL-cholesterol with empagliflozin $25 \mathrm{mg}$. No change in the LDL-cholesterol/HDL-cholesterol ratio was observed with empagliflozin 10 or $25 \mathrm{mg}$. There was a small increase in triglycerides in the placebo and empagliflozin $25 \mathrm{mg}$ groups, with no change in the empagliflozin $10 \mathrm{mg}$ group (Table 5). There were no relevant changes in apolipoprotein A-I in any treatment group. Increases in apolipoprotein B were similar in the placebo and empagliflozin groups (Table 5).

Table 6 Elevations in liver enzymes and bilirubin

\begin{tabular}{llll}
\hline & $\begin{array}{l}\text { Placebo } \\
(\boldsymbol{N}=\mathbf{4 2 0 3})\end{array}$ & $\begin{array}{l}\text { Empagliflozin } \mathbf{1 0} \mathbf{~ m g} \\
(\boldsymbol{N}=\mathbf{4 2 2 1})\end{array}$ & $\begin{array}{l}\text { Empagliflozin 25 } \mathbf{~ m g} \\
(\boldsymbol{N}=\mathbf{4 1 9 6})\end{array}$ \\
\hline ALT and/or AST $\geq 3 \times$ ULN & $59(1.4)$ & $41(1.0)$ & $38(0.9)$ \\
ALT and/or AST $\geq 5 \times$ ULN & $9(0.2)$ & $17(0.4)$ & $21(0.5)$ \\
$\begin{array}{l}\text { ALT and/or AST } \geq 3 \times \text { ULN with } \\
\text { bilirubin } \geq 2 \times \text { ULN }\end{array}$ & $2(<0.1)$ & $5(0.1)$ & $5(0.1)$ \\
\hline
\end{tabular}

Data are $n(\%)$ in participants who received at least one dose of study drug

$A L T$ alanine aminotransferase, $A S T$ aspartate aminotransferase, $U L N$ upper limit of normal 
Table 7 Urine ketone levels: worst recorded measurement on treatment

\begin{tabular}{lccc}
\hline & $\begin{array}{l}\text { Placebo } \\
(\boldsymbol{N}=\mathbf{3 6 4 5})\end{array}$ & $\begin{array}{l}\text { Empagliflozin } \\
\mathbf{1 0} \mathbf{~ m g} \\
(\boldsymbol{N}=\mathbf{3 6 8 2})\end{array}$ & $\begin{array}{l}\text { Empagliflozin } \\
\mathbf{2 5} \mathbf{~ m g} \\
(\boldsymbol{N}=\mathbf{3 6 3 6})\end{array}$ \\
\hline Negative & $2973(81.6)$ & $2822(76.6)$ & $2757(75.8)$ \\
Trace & $511(14.0)$ & $535(14.5)$ & $508(14.0)$ \\
$1+$ & $144(4.0)$ & $256(7.0)$ & $291(8.0)$ \\
$2+$ & $15(0.4)$ & $58(1.6)$ & $73(2.0)$ \\
$3+$ & $2(0.1)$ & $11(0.3)$ & $7(0.2)$ \\
\hline
\end{tabular}

Data are $n(\%)$ in participants who received at least one dose of study drug and had ketone values available at baseline and on treatment

\section{Diabetic Ketoacidosis}

The proportion of participants who had urine ketone levels at least $1+$ was greater in the empagliflozin groups than in the placebo group (Table 7), but the proportion of participants with diabetic ketoacidosis AEs was similar between groups. Diabetic ketoacidosis was reported in $5(0.1 \%), 5(0.1 \%)$, and $1(<0.1 \%)$ participants in the placebo, empagliflozin $10 \mathrm{mg}$, and empagliflozin $25 \mathrm{mg}$ groups, respectively. The incidence of diabetic ketoacidosis was $0.1,0.1$, and less than $0.1 / 100$ patient-years in these groups, respectively. Two participants discontinued treatment with empagliflozin (10 mg) because of diabetic ketoacidosis AEs. No diabetic ketoacidosis AEs were considered to be related to study drug by the investigator. All participants recovered, except for one participant in the empagliflozin $10 \mathrm{mg}$ group for whom the outcome was unknown (at the last follow-up, this participant was scheduled for hospital discharge 5 days after admission for the event). There were no clinically meaningful changes in bicarbonate levels in any treatment group (Table 5).

\section{Acute Pancreatitis}

Acute pancreatitis was reported in 4 (0.1\%), 1 $(<0.1 \%)$, and $4(0.1 \%)$ participants in the placebo, empagliflozin $10 \mathrm{mg}$, and empagliflozin $25 \mathrm{mg}$ groups, respectively. The incidence of acute pancreatitis was 0.1 , less than 0.1 , and $0.1 / 100$ patient-years in these groups, respectively (Table 4).

\section{Lower Limb Amputations}

The frequency of lower limb amputations, based on a manual review of the pooled safety data and $\mathrm{AE}$ narratives, was $1.1 \%$ in all treatment groups (Table 4). Most (131 of 140) cases of lower limb amputation occurred in the EMPA-REG OUTCOME ${ }^{\circledR}$ trial (see Table S1 in the supplementary material). In the EMPA-REG OUTCOME ${ }^{\circledR}$ trial, the proportion of participants with lower limb amputations was similar in participants treated with placebo $(1.8 \%)$ and empagliflozin (1.9\%). Toe amputations occurred in $0.9 \%$ of participants in the placebo group and $1.3 \%$ of participants in the pooled empagliflozin group. In both the empagliflozin and placebo groups, the frequency of lower limb amputations was higher in participants with moderate renal impairment (eGFR 30 to $<60 \mathrm{~mL} / \mathrm{min}$ / $1.73 \mathrm{~m}^{2}$ ) than in those with no/mild renal impairment, and in those using insulin at baseline (see Table $S 1$ in the supplementary material). The frequency of lower limb amputations was higher in participants with a history of peripheral artery disease, microvascular disease, or diabetic foot in all treatment groups. There was no clinically significant difference in the frequency of lower limb amputations between the placebo and empagliflozin groups in subgroups by gender, age, use of diuretics or loop diuretics at baseline, use of concomitant glucose-lowering medications at baseline, or cardiovascular comorbidities (other than peripheral artery disease) (see Table S1 in the supplementary material). The incidences of events potentially related to amputations (peripheral artery obstructive disease events, diabetic foot-related events, relevant infection events, and wound events) were similar in the placebo and empagliflozin groups (Table 4). 


\section{DISCUSSION}

This comprehensive analysis of pooled safety data based on more than 15,000 patient-years' exposure to empagliflozin was undertaken to characterize the safety and tolerability of empagliflozin in patients with T2DM. The results confirmed that empagliflozin is well tolerated in this patient population.

Hypoglycemia is a major concern in patients with T2DM [27]. In this large data set, empagliflozin was not associated with an increased risk of hypoglycemia compared with placebo, except for in participants on background sulfonylurea. Empagliflozin would not be expected to be associated with an increased risk of hypoglycemia given its insulin-independent mechanism of action [1]. However, sulfonylureas, which stimulate insulin secretion, are associated with an increased risk of hypoglycemia [27], and an increase in hypoglycemia has also been reported when other SGLT2 inhibitors are used in combination with a sulfonylurea $[28,29]$. When empagliflozin is used in combination with a sulfonylurea or insulin, a lower dose of the sulfonylurea or insulin should be considered to reduce the risk of hypoglycemia [15].

Treatment with empagliflozin leads to transient natriuresis and increases in urine volume $[2,3]$. The potential for hypotension in patients treated with empagliflozin is acknowledged in the prescribing information [15], particularly in patients who are elderly. In this large data set, the incidence of events consistent with volume depletion was similar between empagliflozin and placebo, except for a greater incidence with empagliflozin in participants aged 75 years or older and in participants receiving loop diuretics at baseline.

In this analysis of pooled data, the incidence of events consistent with UTI was similar in participants treated with empagliflozin and placebo. The incidence of events consistent with genital infection was higher in participants treated with empagliflozin than with placebo, but such events were mild or moderate in most participants and rarely led to treatment discontinuation. An increased risk of genital infections has also been observed with other SGLT2 inhibitors [30, 31].

On the basis of a meta-analysis of phase IIb and phase III clinical trials, the US Food and Drug Administration warned that the SGLT2 inhibitor dapagliflozin may increase the risk of bladder cancer [32] and this is acknowledged in the dapagliflozin product label [33]. Several post-marketing studies are ongoing to ascertain the level of risk. The available safety data for empagliflozin do not suggest an association between empagliflozin and malignancies in patients with T2DM.

Small decreases in eGFR were observed in all treatment groups, with larger declines in the placebo group than in the empagliflozin groups. In the EMPA-REG OUTCOME ${ }^{\circledR}$ trial, an initial decrease in eGFR was observed with empagliflozin. Thereafter, during long-term administration, eGFR remained stable in patients treated with empagliflozin and declined steadily in the placebo group. After cessation of study drug, eGFR increased in the empagliflozin groups, such that eGFR was significantly higher with empagliflozin than placebo at the post-treatment follow-up visit [12]. These observations suggest that the initial decrease in eGFR in patients treated with empagliflozin is due to hemodynamic effects and that empagliflozin has the potential to slow decline in renal function in patients with T2DM [12]. Of note, in our analysis, there was no increase in the incidence of events consistent with decreased renal function, including acute kidney injury, with empagliflozin vs. placebo.

It has been hypothesized that SGLT2 inhibitors might increase the risk of bone fractures because of modulation of renal reabsorption of calcium and phosphate [34, 35]. In this large data set, the incidence of bone fractures was similar in participants treated with empagliflozin and placebo. There were no changes from baseline in calcium or phosphate levels with empagliflozin, and no notable changes from baseline in other bone markers with empagliflozin. Previous studies have found no notable changes in calcium or phosphate levels with empagliflozin in patients with T2DM and chronic kidney disease [4] or in patients with T2DM and established cardiovascular disease [13]. 
Increases in HDL-cholesterol and LDL-cholesterol have been observed in some trials of empagliflozin [5-8], which may be partly due to hemoconcentration [36]. In this pooled analysis, small increases in LDL-cholesterol were observed in the empagliflozin groups; small increases in HDL-cholesterol were observed in the empagliflozin $25 \mathrm{mg}$ group. In this pooled analysis of data from the clinical trial setting, increased urine ketone levels were reported in a greater proportion of participants on empagliflozin than placebo, but the incidence of diabetic ketoacidosis was very low and no higher in participants treated with empagliflozin than placebo. The incidence of events consistent with hepatic injury was similar in participants treated with empagliflozin and placebo.

Regulators have recently completed a review of the available data for possible associations between the SGLT2 inhibitor class and lower limb amputations, concluding that canagliflozin may increase the risk of lower limb amputation [37, 38]. The US Food and Drug Administration has issued a boxed warning to the label for canagliflozin describing the increased risk of leg and foot amputations [38]. A review of the available data for possible associations between SGLT2 inhibitors and acute pancreatitis is ongoing. No evidence of an association between empagliflozin and lower limb amputations or acute pancreatitis was found in this large data set from the clinical trial setting.

Strengths of this analysis include the large sample size and exposure. Limitations include that the studies were of varying durations and that differences between groups were not compared using modelled analyses. The analysis of lower limb amputations should be interpreted with caution because of the manual retrieval and validation of such cases. Overall, the results of this analysis of pooled safety data support a favorable benefit-risk profile of empagliflozin in patients with T2DM.

\section{CONCLUSION}

In this pooled analysis based on more than 15,000 patient-years' exposure to empagliflozin in placebo-controlled trials, empagliflozin 10 and $25 \mathrm{mg}$ were well tolerated in patients with T2DM. Empagliflozin was not associated with a higher rate of hypoglycemic events compared with placebo, except in participants on background sulfonylurea. The incidence of AEs consistent with volume depletion was similar between empagliflozin and placebo, except for a higher incidence with empagliflozin in participants aged 75 years or older and in participants receiving loop diuretics at baseline. Genital infections, but not UTIs, were more frequent in participants treated with empagliflozin than placebo. The incidences of bone fractures, cancer events, renal adverse events, venous thromboembolic events, hepatic injury, acute pancreatitis, lower limb amputations, and diabetic ketoacidosis were not increased with empagliflozin compared with placebo. Further information on the safety and tolerability profile of empagliflozin will be provided by post-marketing surveillance.

\section{ACKNOWLEDGEMENTS}

The studies that provided data for this analysis were funded by Boehringer Ingelheim or the Boehringer Ingelheim \& Eli Lilly and Company Diabetes Alliance. The article processing charges and Open Access fee were funded by Boehringer Ingelheim. Medical writing assistance was supported financially by Boehringer Ingelheim and provided by Melanie Stephens and Wendy Morris of FleishmanHillard Fishburn, London, UK. The authors were fully responsible for all content and editorial decisions, were involved at all stages of manuscript development, and have approved the final version. All named authors meet the International Committee of Medical Journal Editors (ICMJE) criteria for authorship for this manuscript, take responsibility for the integrity of the work as a whole, and have given final approval for the version to be published. All authors had full access to all of the data in this study and take complete responsibility for the integrity of the data and accuracy of the data analysis. 
Disclosures. Sven Kohler is employed by Boehringer Ingelheim. Cordula Zeller is employed by Boehringer Ingelheim. Hristo Iliev is employed by Boehringer Ingelheim. Stefan Kaspers is employed by Boehringer Ingelheim.

Compliance with Ethics Guidelines. All procedures followed were in accordance with the ethical standards of the responsible committee on human experimentation (institutional and national) and with the Helsinki Declaration of 1964, as revised in 2013. An independent ethics committee or institutional review board approved the clinical protocol at each participating center. All participants gave signed and dated informed consent prior to inclusion.

Data Availability. The datasets generated during and/or analyzed during the current study are available from the corresponding author on reasonable request.

Open Access. This article is distributed under the terms of the Creative Commons Attribution-NonCommercial 4.0 International License (http://creativecommons.org/licenses/ by-nc/4.0/), which permits any noncommercial use, distribution, and reproduction in any medium, provided you give appropriate credit to the original author(s) and the source, provide a link to the Creative Commons license, and indicate if changes were made.

\section{REFERENCES}

1. Gallo LA, Wright EM, Vallon V. Probing SGLT2 as a therapeutic target for diabetes: basic physiology and consequences. Diab Vasc Dis Res. 2015;12:78-89.

2. Heise T, Jordan J, Wanner C, et al. Pharmacodynamic effects of single and multiple doses of empagliflozin in patients with type 2 diabetes. Clin Ther. 2016;38:2265-76.

3. Heise T, Jordan J, Wanner C, et al. Acute pharmacodynamic effects of empagliflozin with and without diuretic agents in patients with type 2 diabetes mellitus. Clin Ther. 2016;38:2248-64.
4. Barnett AH, Mithal A, Manassie J, et al. Efficacy and safety of empagliflozin added to existing antidiabetes treatment in patients with type 2 diabetes and chronic kidney disease: a randomised, double-blind, placebo-controlled trial. Lancet Diabetes Endocrinol. 2014;2:369-84.

5. Haering HU, Merker L, Seewaldt-Becker E, et al. Empagliflozin as add-on to metformin plus sulfonylurea in patients with type 2 diabetes: a 24 -week, randomized, double-blind, placebo-controlled trial. Diabetes Care. 2013;36:3396-404.

6. Haering HU, Merker L, Seewaldt-Becker E, et al. Empagliflozin as add-on to metformin in patients with type 2 diabetes: a 24-week, randomized, double-blind, placebo-controlled trial. Diabetes Care. 2014;37:1650-9.

7. Kovacs CS, Seshiah V, Swallow R, et al. Empagliflozin improves glycaemic and weight control as add-on therapy to pioglitazone or pioglitazone plus metformin in patients with type 2 diabetes: a 24 -week, randomized, placebo-controlled trial. Diabetes Obes Metab. 2014;16:147-58.

8. Roden M, Weng J, Eilbracht J, et al. Empagliflozin monotherapy with sitagliptin as an active comparator in patients with type 2 diabetes: a randomised, double-blind, placebo-controlled, phase 3 trial. Lancet Diabetes Endocrinol. 2013;1:208-19.

9. Rosenstock J, Jelaska A, Frappin G, et al. Improved glucose control with weight loss, lower insulin doses, and no increased hypoglycemia with empagliflozin added to titrated multiple daily injections of insulin in obese inadequately controlled type 2 diabetes. Diabetes Care. 2014;37:1815-23.

10. Rosenstock J, Jelaska A, Zeller C, Kim G, Broedl UC, Woerle HJ. Impact of empagliflozin added-on to basal insulin in type 2 diabetes inadequately controlled on basal insulin: a 78-week randomized, double-blind, placebo-controlled trial. Diabetes Obes Metab. 2015;17:936-48.

11. Tikkanen I, Narko K, Zeller C, et al. Empagliflozin reduces blood pressure in patients with type 2 diabetes and hypertension. Diabetes Care. 2015;38:420-8.

12. Wanner C, Inzucchi SE, Lachin JM, et al. Empagliflozin and progression of kidney disease in type 2 diabetes. N Engl J Med. 2016;375:323-34.

13. Zinman B, Wanner C, Lachin JM, et al. Empagliflozin, cardiovascular outcomes, and mortality in type 2 diabetes. N Engl J Med. 2015;373:2117-28.

14. Kohler S, Salsali A, Hantel S, et al. Safety and tolerability of empagliflozin in patients with type 2 diabetes. Clin Ther. 2016;38:1299-313. 
15. Boehringer Ingelheim Pharmaceuticals, Inc., Jardiance (empagliflozin) US Prescribing Information; 2016. http://docs.boehringer-ingelheim.com/ Prescribing\%20Information/PIs/Jardiance/jardiance. pdf. Accessed 19 May 2017.

16. Ferrannini E, Baldi S, Frascerra S, et al. Shift to fatty substrate utilization in response to sodium-glucose cotransporter 2 inhibition in subjects without diabetes and patients with type 2 diabetes. Diabetes. 2016;65:1190-5.

17. Ferrannini E, Seman L, Seewaldt-Becker E, Hantel S, Pinnetti S, Woerle HJ. A phase IIb, randomized, placebo-controlled study of the SGLT2 inhibitor empagliflozin in patients with type 2 diabetes. Diabetes Obes Metab. 2013;15:721-8.

18. Heise T, Seewaldt-Becker E, Macha S, et al. Safety, tolerability, pharmacokinetics and pharmacodynamics following 4 weeks' treatment with empagliflozin once daily in patients with type 2 diabetes. Diabetes Obes Metab. 2013;15:613-21.

19. Kadowaki T, Haneda M, Inagaki N, et al. Empagliflozin monotherapy in Japanese patients with type 2 diabetes mellitus: a randomized, 12-week, double-blind, placebo-controlled, phase II trial. Adv Ther. 2014;31:621-38.

20. Kanada S, Koiwai K, Taniguchi A, Sarashina A, Seman L, Woerle HJ. Pharmacokinetics, pharmacodynamics, safety and tolerability of 4 weeks' treatment with empagliflozin in Japanese patients with type 2 diabetes mellitus. J Diabetes Investig. 2013;4:613-7.

21. Nishimura R, Tanaka Y, Koiwai K, et al. Effect of empagliflozin monotherapy on postprandial glucose and 24-hour glucose variability in Japanese patients with type 2 diabetes mellitus: a randomized, double-blind, placebo-controlled, 4-week study. Cardiovasc Diabetol. 2015;14:11.

22. Rosenstock J, Seman LJ, Jelaska A, et al. Efficacy and safety of empagliflozin, a sodium glucose cotransporter 2 (SGLT2) inhibitor, as add-on to metformin in type 2 diabetes with mild hyperglycaemia. Diabetes Obes Metab. 2013;15:1154-60.

23. Roden M, Merker L, Christiansen AV, et al. Safety, tolerability and effects on cardiometabolic risk factors of empagliflozin monotherapy in drug-naïve patients with type 2 diabetes: a double-blind extension of a phase III randomized controlled trial. Cardiovasc Diabetol. 2015;14:154.

24. Merker L, Haering HU, Christiansen AV, et al. Empagliflozin as add-on to metformin in people with type 2 diabetes. Diabet Med. 2015;32:1555-67.
25. Haering HU, Merker L, Christiansen AV, et al. Empagliflozin as add-on to metformin plus sulfonylurea in patients with type 2 diabetes. Diabetes Res Clin Pract. 2015;110:82-90.

26. Kovacs CS, Seshiah V, Merker L, et al. Empagliflozin as add-on to pioglitazone with or without metformin in patients with type 2 diabetes. Clin Ther. 2015;37:1773-88.

27. Inzucchi SE, Bergenstal RM, Buse JB, et al. Management of hyperglycemia in type 2 diabetes: a patient-centered approach: position statement of the American Diabetes Association (ADA) and the European Association for the Study of Diabetes (EASD). Diabetes Care. 2012;35:1364-79.

28. Ptaszynska A, Johnsson KM, Parikh SJ, de Bruin TW, Apanovitch AM, List JF. Safety profile of dapagliflozin for type 2 diabetes: pooled analysis of clinical studies for overall safety and rare events. Drug Saf. 2014;37:815-29.

29. Yang XP, Lai D, Zhong XY, Shen HP, Huang YL. Efficacy and safety of canagliflozin in subjects with type 2 diabetes: systematic review and meta-analysis. Eur J Clin Pharmacol. 2014;70:1149-58.

30. Johnsson KM, Ptaszynska A, Schmitz B, et al. Vulvovaginitis and balanitis in patients with diabetes treated with dapagliflozin. J Diabetes Complicat. 2013;27:479-84.

31. Rosiak M, Grzeszczak S, Kosior DA, Postuła M. Emerging treatments in type 2 diabetes: focus on canagliflozin. Ther Clin Risk Manag. 2014;10:683-9.

32. FDA briefing document: NDA 202293 dapagliflozin oral tablets, 5 and $10 \mathrm{mg}$; 2013. http://www.fda. gov/downloads/AdvisoryCommittees/Committees MeetingMaterials/Drugs/EndocrinologicandMetab\% 20olicDrugsAdvisoryCommittee/UCM378076.pdf. Accessed 19 May 2017.

33. AstraZeneca and Bristol-Myers Squibb. Forxiga (dapagliflozin) US prescribing information; 2014. http://www.azpicentral.com/farxiga/pi_farxiga.pdf. Accessed 19 May 2017.

34. Blaine J, Chonchol M, Levi M. Renal control of calcium, phosphate, and magnesium homeostasis. Clin J Am Soc Nephrol. 2015;10:1257-72.

35. Taylor SI, Blau JE, Rother KI. Possible adverse effects of SGLT2 inhibitors on bone. Lancet Diabetes Endocrinol. 2015;3:8-10.

36. Lund SS, Sattar N, Salsali A, Crowe S, Broedl UC, Ginsberg HN. Potential relevance of changes in haematocrit to changes in lipid parameters with 
empagliflozin in patients with type 2 diabetes. Diabetologia. 2015;58(suppl 1):S360[750].

37. EMA Pharmacovigilance Risk Assessment Committee recommendation: PRAC concludes that diabetes medicine canagliflozin may contribute to risk of toe amputation 2017. http://www.ema.europa.eu/docs/ en_GB/document_library/Referrals_document/SGL T2_inhibitors_Canagliflozin_20/Recommendation_
provided_by_Pharmacovigilance_Risk_Assessment_ Committee/WC500221431.pdf. Accessed 19 May 2017.

38. US Food \& Drug Administration. Canagliflozin (Invokana, Invokamet): drug safety communication - increased risk of leg and foot amputations. 2017. Available at: https://www.fda.gov/Drugs/DrugSafety/ ucm557507.htm. Accessed 19 May 2017. 